JIIF (Jurnal Ilmu dan Inovasi Fisika)

Vol. 02, No. 02 (2018) 155 - 161

(C) Departemen Fisika FMIPA Universitas Padjadjaran

\title{
ANALISIS PENDEKATAN EMPIRIS PGA (PEAK GROUND ACCELERATION) PULAU BALI MENGGUNAKAN METODE DONOVAN, MC. GUIRRE, DAN M.V. MICKEY
}

\author{
EMI ULFIANA ${ }^{1 *}$, SAID A. RUMY ${ }^{2}$,RIAN PRATAMA ${ }^{3}$, PUJI ARIYANTO ${ }^{4}$ \\ Prodi Geofisika, \\ ${ }^{1,2,3,4}$ Sekolah Tinggi Meteorologi Klimatologi dan Geofisika (STMKG) \\ Jl. Perhubungan I no.5, Pondok Betung, Pondok Aren, Tangerang Selatan, Banten, 15221 \\ *Email : emiulfiana226@gmail.com
}

\begin{abstract}
Abstrak.Salah satu faktor yang mempengaruhi nilai percepatan tanah maksimum atau Peak Ground Acceleration (PGA) adalah faktor lokal yang dapat berupa keadaan geologi atau karakteristik suatu wilayah. Hal ini menunjukkan adanya perbedaan nilai PGA pada suatu wilayah terkait perbedaan karakteristik geologi. Nilai PGA pada umumnya didapatkan dari hasil observasi rekaman akselerograf, namun dikarenakan keterbatasan alat akselerograf pada suatu wilayah, maka perhitungan PGA dilakukan dengan pendekatan empiris. Penelitian ini bertujuan untuk menganalisis rumus empiris Donovan, Mc. Guirre, dan M.V. Mickey terhadap kecocokan nilai PGA pulau Bali berdasarkan peta guncangan tanah, baik berupa Shakemap maupun peta Seismic Hazard pulau Bali. Penelitian menggunakan 738 data parameter gempa bumi dari katalog BMKG dan USGS pada rentang waktu Januari 1963 hingga Oktober 2017. Hasil penelitian menunjukkan bahwa dibandingkan dengan dua metode empiris lainnya, metode empiris Donovan adalah pendekatan empiris paling baik yang dapat digunakan untuk menghitung nilai PGA di Pulau Bali.
\end{abstract}

Kata kunci :PGA, Metode empiris, Shakemap, Peta Seismic Hazard

\begin{abstract}
One of the factors affecting the Peak Ground Acceleration (PGA) is a local factor that can be a geological state or a region's characteristics. This shows the difference of PGA value in an area related to different geological characteristics. PGA values are generally obtained from the observation of accelerometer recording, but due to the limitation of the accelerometer in a region, the PGA calculation is done by empirical approach. This study aims to analyze the empirical formula of Donovan, Mc. Guirre, and M.V. Mickey against the suitability of Bali Island PGA value based on ground shake map, either Shakemap or Seismic Hazard map of Bali island. The study used 738 earthquake parameter data from BMKG and USGS catalogs from January 1963 to October 2017. The results show that compared to the other two empirical methods, Donovan's empirical method is the best empirical approach that can be used to calculate the PGA value on the Island of Bali.
\end{abstract}

Keywords :PGA, Empirical Method, Shakemap, Seismic Hazard Map

\section{Pendahuluan}

Indonesia terletak dalam wilayah petemuan 3 lempeng tektonik utama, yakni lempeng Eurasia, Indo-Australia, dan Pasifik. Pulau Bali termasuk dalam bagian sesimotektonik Indonesia. Pulau Bali dilalui jalur pegunungan Mediteranian dan juga didalamnya terdapat zona subduksi akibat pertemuan lempeng Eurasia dan Indo-Australia. Pulau Bali adalah salah satu wilayah dengan aktivitas seismik yang tinggi. Hal ini berkaitan dengan subduksi lempeng di bawah paparan Sunda 
dan aktivitas tepi benua Australia, serta kelanjutan garis busur Sunda ke arah timur yang bertemu dengan busur Banda.

Aktivitas seismik yang tinggi ditandai dengan tingkat kejadian gempa bumi yang terjadi pada suatu wilayah. Gempa bumi adalah peristiwa bergetarnya bumi secara tiba-tiba akibat adanya pelepasan energi yang ditandai dengan patahnya lapisan batuan pada kerak bumi. Gempa bumi menyebabkan banyaknya korban jiwa pun harta. Adalah reruntuhan bangunan yang menjadi hal utama penyebab adanya korban dalam gempa bumi. Perlu adanya upaya mitigasi sebagai upaya minimalisasi dampak gempa bumi. Salah satu upaya tersebut adalah dengan mengetahui informasi gerakan tanah pada suatu wilayah. Informasi gerakan tanah dapat berupa guncangan maksimum tanah yang pernah terjadi pada suatu wilayah. Informasi tersebut dapat dimanfaatkan untuk perancangan bangunan tahan gempa, pemetaan PSHA (Probabilistic Seismic Hazard Analysis), termasuk dapat digunakan untuk mengetahui karakteristik tanah pada suatu wilayah.

Parameter guncangan maksimum tanah atau Peak Ground Acceleration (PGA) dipengaruhi oleh tiga hal, yakni : sumber gempa bumi (magnitudo, jenis sesar, dan hal lain yang berkaitan dengan sumber gempa bumi), raypath (jalur penjalaran gelombang termasuk di dalamnya jarak hiposenter), serta faktor lokal yang dapat berupa keadaan geologi atau karakteristik suatu wilayah. Hal ini menunjukkan adanya perbedaan nilai PGA pada suatu wilayah terkait perbedaan karakteristik geologi. Nilai PGA pada umumnya didapatkan dari hasil observasi rekaman akselerograf. Namun, akselerograf tidak tersebar secara merata di seluruh wilayah Indonesia. Akibat keterbatasan tersebut, perlu adanya sebuah pendekatan empiris untuk menghitung nilai PGA pada suatu wilayah. Metode dengan pendekatan empiris telah banyak dilakukan oleh para ahli, seperti Donovan, Mc. Guirre, M.V Mickey, dan lain sebagainya.

Penelitian ini bertujuan untuk menganalisis kecocokan suatu pendekatan empiris terhadap nilai PGA pulau Bali berdasarkan peta guncangan tanah, baik berupa Shakemap maupun peta Seismic Hazard pulau Bali. Peta guncangan tanah adalah peta yang menunjukkan persebaran nilai percepatan tanah maksimum pada suatu wilayah. Jika Shakemap hanya menggambarkan persebaran nilai PGA dan intensitas guncangan tanah yang dirasakan di permukaan pada suatu kejadian gempa, maka sedikit berbeda dengan peta Seismic Hazard. Peta Seismic Hazard adalah sebuah peta yang menggambarkan persebaran nilai percepatan tanah maksimum pada suatu wilayah dalam jangka waktu dan kemungkinan tertentu. Peta guncangan tanah tersebut, dapat dijadikan acuan mengenai kecocokan pendekatan empiris yang digunakan. Hal tersebut terkait bahwa peta guncangan tanah diperoleh dari penilaian keseluruhan aspek atau parameter yang berupa data observasi. Data observasi tersebut, yakni data PGA dan MMI (Modified Mercalli Intensity) observasi, serta data mikrozonasi yang berupa kecepatan gelombang $\mathrm{S}$ pada kedalaman $30 \mathrm{~m}$ (Vs 30). 


\section{Metode Penelitian}

Penelitian meliputi wilayah pulau Bali dengan menggunakan 738 data parameter gempa bumi mulai dari Januari 1963 hingga Oktober 2017. Data diperoleh dari katalog gempa bumi BMKG dan USGS. Parameter gempa bumi yang telah didapat, selanjutnya dilakukan proses pengolahan. Hal pertama yang dilakukan adalah pembuatan grid sebagai titik acuan untuk perhitungan jarak hiposenter. Metode pendekatan empiris yang digunakan adalah metode empiris Donovan, Mc. Guirre, dan M. V. Mickey.

Donovan :

$$
\alpha=\frac{1080 \exp (0,5 M s)}{(\Delta+25)^{1.32}}
$$

Mc Guirre :

$$
\alpha=\frac{472,3 \exp (0,27 M s)}{(\Delta+25)^{1.301}}
$$

M.V. Mickey :

$$
\alpha=\frac{(3,04) 10^{-1} \cdot 10^{0.74 M s}}{\Delta^{1 / 4}}
$$

Dengan :

$\alpha=$ percepatan tanah (gals)

Ms = Magnitudo gelombang permukaan

$\Delta=$ Jarak Hiposenter $(\mathrm{Km})$

Dengan anggapan bahwa bumi bulat, perhitungan hiposenter didapatkan sebagai berikut :

$$
\begin{gathered}
X_{s}=r \cos \emptyset \cos \theta \\
Y_{S}=r \cos \emptyset \sin \theta \\
Z_{s}=r \sin \emptyset .
\end{gathered}
$$

Dengan :

$$
\begin{aligned}
& \emptyset=\frac{\emptyset_{s} * \pi}{180}(\mathrm{rad}) \\
& \theta=\frac{\theta_{s} * \pi}{180}(\mathrm{rad}) \\
& r=\text { jari-jari bumi }(6371 \mathrm{~km}) \\
& \emptyset_{s}=\text { lintang pengamat (derajat) } \\
& \theta_{s}=\text { bujur pengamat (derajat) } \\
& X_{s}, Y_{s}, Z_{s}=\text { koordinat titik pengamat atau titik acuan }
\end{aligned}
$$

Posisi sumber gempa : 


$$
\begin{gathered}
X_{h}=(r-h) \cos \emptyset \cos \theta \\
Y_{h}=(r-h) \cos \emptyset \sin \theta \\
Z_{h}=(r-h) \sin \emptyset
\end{gathered}
$$

Dengan :

$$
\begin{aligned}
& \emptyset=\frac{\emptyset_{h} * \pi}{180}(\mathrm{rad}) \\
& \theta=\frac{\theta_{h} * \pi}{180}(\mathrm{rad}) \\
& h=\text { kedalaman gempa bumi } \\
& \emptyset_{h}=\text { lintang episenter (derajat) } \\
& \theta_{h}=\text { bujur episenter (derajat) } \\
& X_{h}, Y_{h}, Z_{h}=\text { koordinat episenter }
\end{aligned}
$$

Jarak hiposenter $(\Delta)$

$$
\Delta=\sqrt{\left(X_{h}-X_{S}\right)^{2}+\left(Y_{h}-Y_{S}\right)^{2}+\left(Z_{h}-Z_{S}\right)^{2} K m}
$$

Magnitude yang diperoleh dari katalog gempa BMKG berupa Magnitudo lokal (Ml), sedang dari katalog USGS berupa Magnitude lokal (Ml), Magnitudo momen (Mw), Magnitudo gelombang body (Mb), dan Magnitudo surface (Ms). Sehingga, perlu dilakukan konversi magnitudo ke Ms, agar dapat dilakukan perhitungan empiris sesuai dengan ketentuan rumus empiris Donovan, Mc. Guirre, dan M.V. Mickey. Hubungan beberapa magnitudo tersebut sebagai berikut.

$$
\begin{gathered}
M b=0,56 M s+2,9 \\
M b=1,7+0,8 M l-M l^{2} \\
M s=\left(\frac{3}{2} M w-9,1\right) / 1,5
\end{gathered}
$$

Berdasarkan persamaan (1), (2), dam (3), didapatkan persebaran nilai PGA dalam gals. Untuk dapat dibandingkan menggunakan peta guncangan tanah, baik berupa shakemap maupun peta hazard seismic, maka hasil tersebut harus dikonversi ke dalam satuan gals.

$$
1 \text { Gals }=0,00101972 \text { g-units }
$$

\section{Hasil dan Pembahasan}

Hasil penelitian berupa grafik statistik hasil perhitungan PGA ketiga metode empiris dan berupa peta persebaran PGA. 


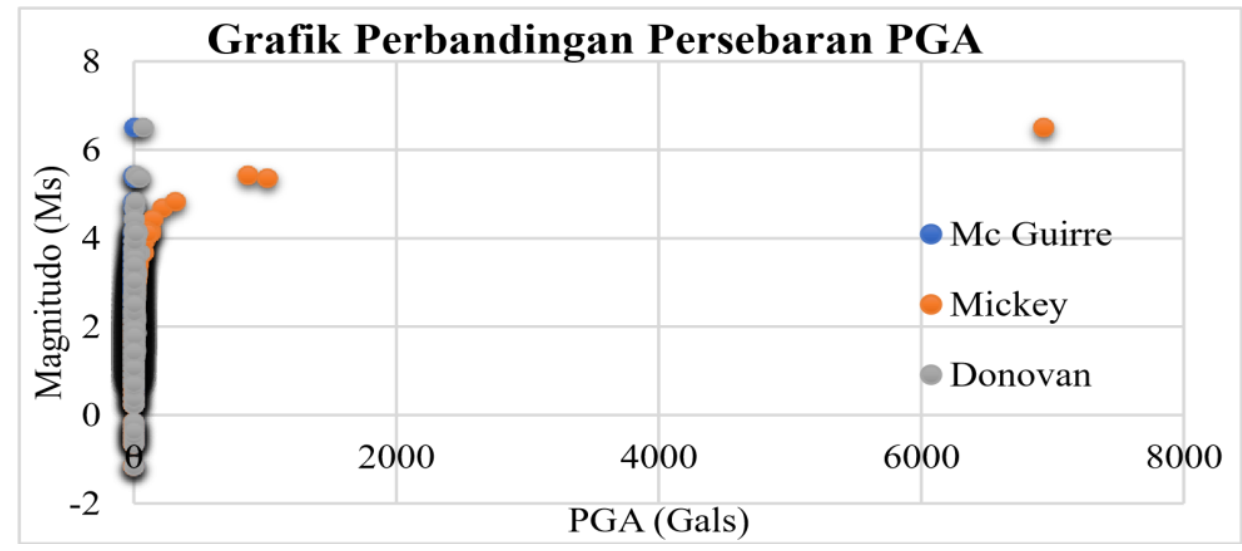

Gambar 1.Grafik PGA terhadap Magnitudo

Pada gambar 1, terlihat bahwa metode empiris M.V. Mickey sudah tidak bersifat linear ketika Ms $>5$. Artinya, rumusan M.V. Mickey sudah tidak cocok digunakan untuk menghitung Ms $>5$. Sedangkan rumusan Donovan dan Mc Guirre, cocok digunakan untuk di semua jenis Magnitudo.

Berdasarkan hasil yang ditunjukkan pada gambar 1, maka nilai PGA yang akan dibandingkan selanjutnya adalah nilai PGA dengan $\mathrm{Ms}>5$. Untuk perbandingannya dengan Shakemap, digunakan event gempa 26 Maret 2015 yang berasal dari katalog gempa BMKG. Oleh karena Shakemap dan event sama-sama berasal dari katalog gempa BMKG, maka tidak perlu adanya konversi magitudo untuk menyetarakan nilai magnitudo sebagai langkah untuk membandingkan antar keduanya. 

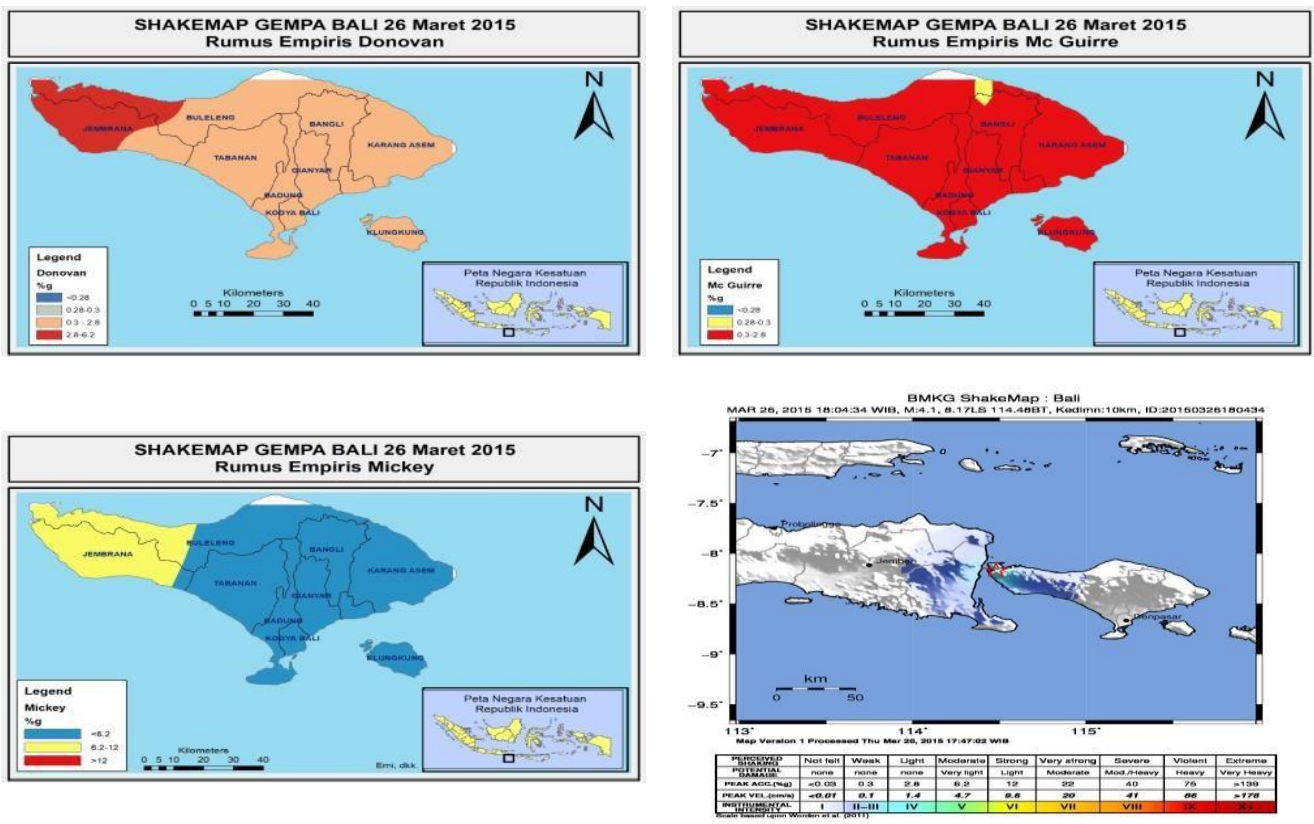

Gambar 2. Shakemap dan persebaran nilai PGA pada event 26 Maret 2015 menggunakan rumus empiris Donovan, Mc. Guirre, dan M.V. Mickey
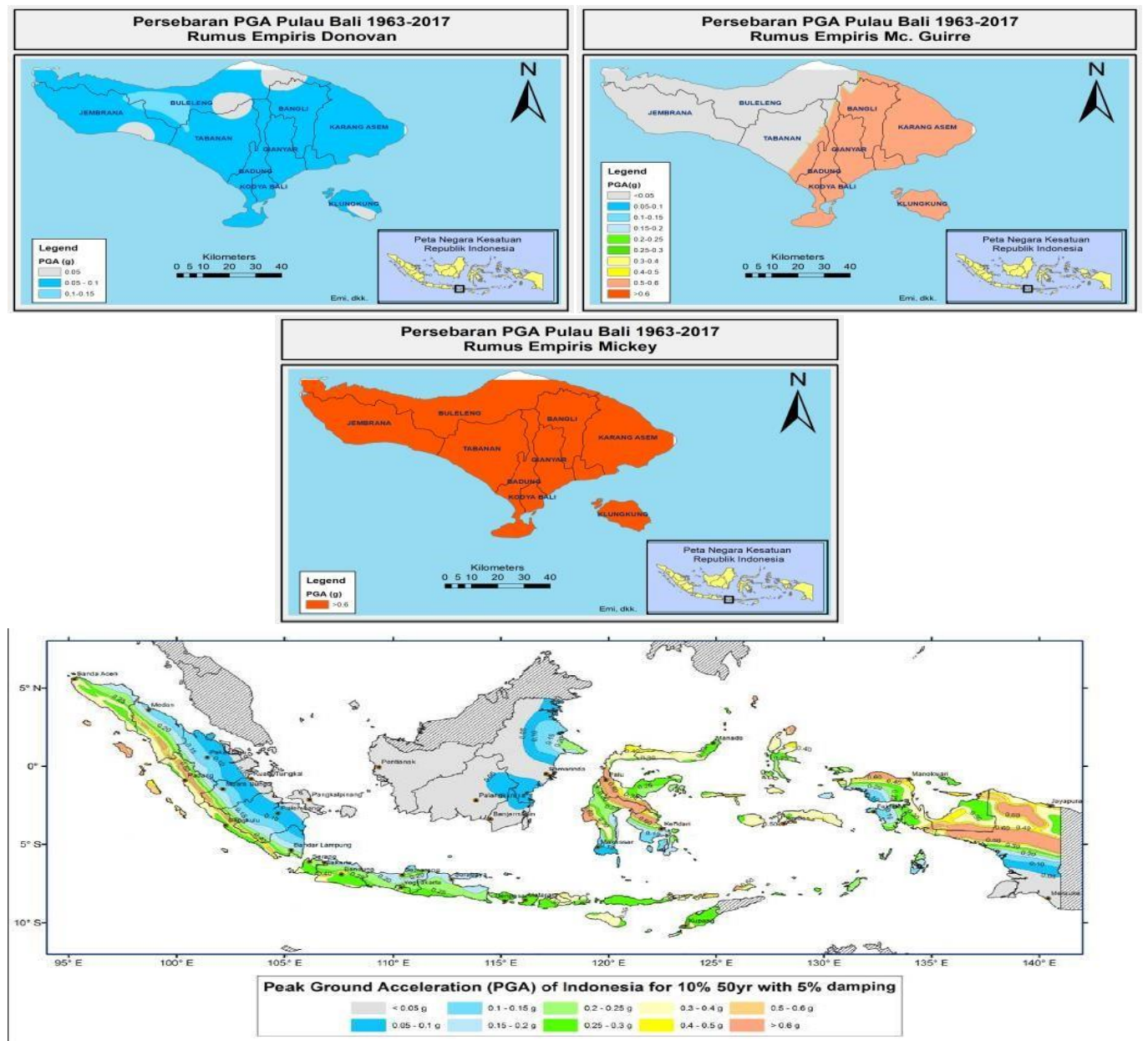

Gambar 3. Peta Hazard Seismic dan persebaran nilai PGA tertinggi Januari 1963-Oktober 2017 Sumber :https://reliefweb.int/sites/reliefweb.int/files/resources/B2C056B225150DADC12577650039D2A8-map 
Dari ketiga peta persebaran PGA berdasarkan metode empiris pada gambar 2, metode empiris yang paling mendekati Shakemap adalah metode empiris Donovan, yangmana pada daerah sekitar hiposenter, nilai PGA yang dirasakan sebesar 2.8-6.2 \%g. Nilai tersebut hampir sama dengan nilai PGA yang ada pada shakemap, yakni nilai PGA sebesar 2.8-6.2 \%g ada pada daerah sekitar hiposenter.

Ditunjukkan oleh gambar 3, nilai PGA maksimum dalam rentang waktu Januari 1963 hingga Oktober 2017, pada setiap metode empiris memiliki perbedaan yang sangat kontras. Jika dibandingkan dengan peta Seismic Hazard Indonesia, persebaran PGA dengan rumusan empiris yang paling mendekati adalah metode empiris Donovan. Pada metode empiris Donovan, nilai PGA yang paling dominan untuk keseluruhan Pulau Bali adalah sebesar 0.05-0.1 g. Sedangkan pada peta Hazard Seismic nilai PGA untuk pulau Bali ada pada kisaran 0.25-0.3 g. Meskipun nilai PGA yang dihasilkan cukup berbeda antara metode Donovan dengan Peta Seismic Hazard, namun diantara ketiga metode yang dilakukan, metode empiris Donovan adalah yang paling mendekati untuk pulau Bali. Nilai PGA tertinggi berdasarkan metode empiris Donovan berada di sekitar kabupaten Buleleng, dengan kisaran PGA 0.1-0.15 g.

\section{Kesimpulan}

Berdasarkan hasil penelitian yang diperoleh, disimpulkan bahwa rumusan Donovan dan Mc. Guirre cocok digunakan untuk menghitung event gempa, baik Ms $<5$, pun Ms $>5$. Sedangkan, rumusan M.V. Mickey tidak cocok digunakan untuk menghitung nilai PGA pada sebuah event dengan Ms $>5$. Hasil perbandingan rumusan empiris Donovan, Mc. Guirre, M.V. Mickey dengan Shakemap dan peta Seismic hazard, diperoleh bahwa metode pendekatan empiris Donovan adalah pendekatan empiris yang paling cocok digunakan di Pulau Bali dibandingkan dengan pendekatan empiris Mc. Guirre dan M.V. Mickey.

\section{Daftar Pustaka}

1. D. M. Fildayen, Penentuan Formula Empiris Percepatan Tanah Maksimum di Zona Gempa Tasikmalaya Tanggal 2 September 2009. Skripsi : UIN Syarif Hidayatullah (2010).

2. Douglas, John, Ground Motion Prediction Equation 1964-2017. United Kingdom (2017).

3. F. Ahmad, Analisis Parameter Gempa, b Value dan PGA di Daerah Papua. Skripsi : UIN Syarif Hidayatullah (2011).

4. Gempa bumi. Retrieved from : http://www.bmkg.go.id

5. Handewi, Istiqorini, dkk, Analisis Percepatan Tanah Maksimum Gempa Bumi Tektonik Wilayah Jawa Timur Menggunakan Metode Donovan. Universitas Negeri Malang (2014). 